\title{
Current Status of Image-Enhanced Endoscopy for Early Identification of Esophageal Neoplasms
}

\author{
Shin Hee Kim and Su Jin Hong \\ Digestive Disease Center and Research Institute, Department of Internal Medicine, Department of Biostatistics, Soonchunghyang \\ University School of Medicine, Bucheon, Korea
}

Advanced esophageal cancer is known to have a poor prognosis. The early detection of esophageal neoplasms, including esophageal dysplasia and early esophageal cancer, is highly important for the accurate treatment of the disease. However, esophageal dysplasia and early esophageal cancer are usually subtle and can be easily missed. In addition to the early detection, proper pretreatment evaluation of the depth of invasion of esophageal cancer is very important for curative treatment. The progression of non-invasive diagnosis via image-enhanced endoscopy techniques has been shown to aid the early detection and estimate the depth of invasion of early esophageal cancer and, as a result, may provide additional opportunities for curative treatment. Here, we review the advancement of image-enhanced endoscopy-related technologies and their role in the early identification of esophageal neoplasms. Clin Endosc 2021;54:464-476

Key Words: Diagnostic imaging; Early detection of cancer; Esophageal neoplasms; Narrow-band imaging

\section{INTRODUCTION}

Esophageal cancer ranks seventh in terms of incidence and is the sixth most common cause of cancer-related mortality worldwide. ${ }^{1}$ Esophageal squamous cell carcinoma (ESCC) is the most common histological type of esophageal cancer, ${ }^{2-4}$ and the incidence of esophageal adenocarcinoma (EAC) is increasing, especially in Western countries. ${ }^{5}$ Esophageal dysplasia, including low-grade intraepithelial neoplasia, high-grade intraepithelial neoplasia (HGIN), and Barrett's esophagus (BE) are the precursor lesions of ESCC and EAC. ${ }^{6,7}$

Despite the improvement in treatment modalities, the 5-year survival of esophageal cancer is between 10\% and 25\%

Received: June 10, 2021 Revised: July 12, 2021

Accepted: July 14, 2021

Correspondence: $\mathrm{Su}$ Jin Hong

Digestive Disease Center, Soonchunghyang University Bucheon Hospital, 170,

Jomaru-ro, Bucheon-si, Gyeonggi-do 14584, Korea

Tel: +82-32-621-5094, Fax: +82-32-621-5080, E-mail: sjhong@schmc.ac.kr ORCID: https://orcid.org/0000-0003-2012-0360

It is the invited review article.

cc This is an Open Access article distributed under the terms of the Creative Commons Attribution Non-Commercial License (http://creativecommons.org/ licenses/by-nc/3.0) which permits unrestricted non-commercial use, distribution, and reproduction in any medium, provided the original work is properly cited. and the mortality rate is still high due to an advanced stage at diagnosis. ${ }^{4,89}$ However, the prognosis can be improved up to $95 \%$ when it is detected and treated as an early-stage disease that can be treated with endoscopic resection. ${ }^{10}$ Predicting the depth of the invasion of early esophageal cancer is important to determine a proper candidate lesion for endoscopic resection since the invasion depth has a reliable relationship with the rate of lymph node metastasis. ${ }^{11-13}$ The 5-year cause-specific survival and 5-year overall survival rates were reported to be 98-100\% and $85-95 \%$ in endoscopic submucosal dissection (ESD) of the depth of the epithelium (EP) or lamina propria mucosae (LPM), respectively. ${ }^{14}$

White-light endoscopy (WLE) is the standard modality for detecting esophageal neoplastic lesions. However, the endoscopic features of early esophageal neoplastic lesions under WLE are subtle and isochromatic. ${ }^{15,16}$ In addition, BE-related dysplasia or early EAC is prone to remain undetected when using standard WLE since these lesions are flat and unremarkable. ${ }^{17}$ A multicenter randomized controlled trial (RCT) found that the sensitivity of WLE for superficial ESCC was less than $60 \% .{ }^{15}$ Image-enhanced endoscopy (IEE), including dyebased chromoendoscopy and virtual chromoendoscopy with or without magnifying endoscopy (ME) is a new diagnostic 
endoscopic technique that has been helpful in the detection of tumors and predicting the depth of invasion of esophageal cancer. This review aimed to provide an overview of the current status and advancements of IEE-related technologies for the early detection of esophageal neoplasms.

\section{CONVENTIONAL CHROMOENDOSCOPY}

Conventional chromoendoscopy is a technique that enhances the mucosal structural details by spraying dyes onto mucosal surfaces. It assists in distinguishing the abnormal mucosa from the normal mucosa by contrast to the mucosal surface by permeating depressed mucosal folds or grooves (i.e., contrast dye) or interaction with specific intracellular materials or elements (i.e., absorptive dye).

\section{Lugol's iodine}

Lugol's iodine is the most widely used absorptive dye for detecting esophageal squamous cell dysplasia and ESCC. Mature esophageal squamous epithelium contains abundant glycogen, which is stained a dark brown color with iodine; however, the dysplastic lesion exhibits either decreased or absent glycogen content as well as demonstrates a characteristic of unstained appearance on inspection following application of Lugol's iodine. The unstained area of Lugol's iodine is useful to detect esophageal squamous cell dysplasia or ESCC. ${ }^{18}$ Lugol's chromoendoscopy (LCE) is the gold standard for the detection of ESCC. LCE can help identify the borders of esophageal cancer and facilitate precise biopsies. The European Society of Gastroenterology Endoscopy guidelines recommend that it should be used to demarcate the lateral margins of superficial tumors and to identify synchronous esophageal lesions. ${ }^{19}$ One prospective observational study investigated the prevalence of esophageal cancer in patients with primary head and neck cancer using LCE and WLE. It has been shown that the diagnosis of advanced and invasive esophageal cancer was equivalent in both modalities; however, the LCE can detect HGIN more precisely than WLE (100\% vs. $55 \%){ }^{20}$ The sensitivity of LCE for the diagnosis of squamous cell dysplasia and ESCC ranges from $91 \%$ to $100 \% .{ }^{18,21-24}$ It would hard to be stained by Lugol's Iodine after changing into HGIN and ESCC due to lack of cells containing glycogen. Therefore, these lesions are observed with a pinkish color after the brown color of the iodine solution has faded. ${ }^{25}$ The pink-color discoloration within the Lugol-voiding area observed after 2 to 3 minutes from the staining (i.e. pink-color sign, Fig. 1) has been significantly correlated with HGIN and ESCC on histology (sensitivity was $91.9 \%$ and specificity was $94.0 \%) .{ }^{25}$ Nevertheless, LCE increases the duration of endoscopic examination and can cause mucosal irritation leading to adverse events, such as allergic reaction, retrosternal pain, and esophageal erosion or ulcers. ${ }^{26,27}$ Occasionally, subtle early neoplastic lesions could temporarily disappear because of mucosal inflammation and interfere with endoscopic treatment for days to weeks. ${ }^{28} \mathrm{~A}$ recent double-blind RCT, which aimed to evaluate patient discomfort with different iodine concentrations found that a $1 \%$ iodine solution leads to significantly lesser pain than a $2 \%$ iodine solution $(p=0.02)$ with non-inferior visibility. ${ }^{29}$

\section{Acetic acid}

Acetic acid (AA) is a useful dye for the early identification of dysplastic BE lesions. AA improves the visualization of the mucosal surface via reversible acetylation of nuclear proteins. The reaction only lasts for a few minutes, and dysplastic tissues lose the acetowhitening quicker than surrounding

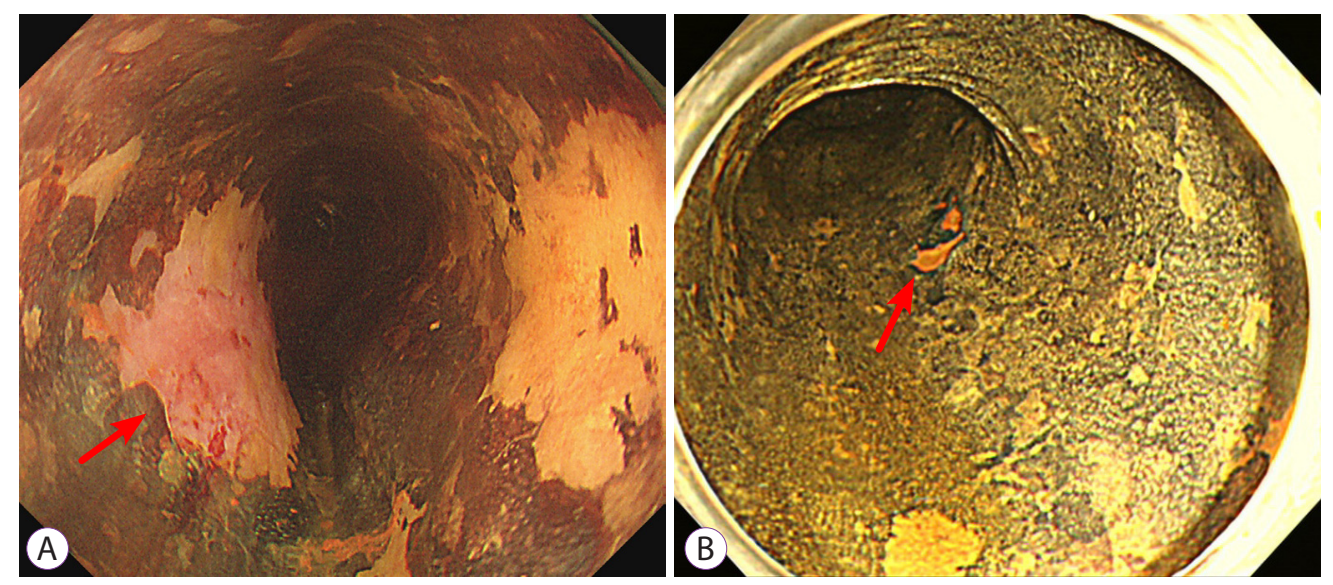

Fig. 1. Pink-color sign. (A, B) The pink-color discoloration within the Lugol-voiding area was observed 2-3 min after staining (arrow). 
intestinal-type columnar metaplasia. ${ }^{30,31}$ Two large trials have reported the effectiveness of $\mathrm{AA}$ in detecting neoplasms in $\mathrm{BE}$ in a high-risk population. ${ }^{31,32}$ Additionally, one retrospective large cohort study showed that AA-guided biopsies significantly improved the detection rate of neoplasia ( $2 \%$ vs. $12.5 \%$, $p=0.0001$ ) and requires 15 times fewer biopsies on per-biopsy analysis $(0.025$ vs. $0.0017, p=0.000) .^{33}$ Recent meta-analyses showed that targeted biopsies with AA are useful for detecting HGIN and early adenocarcinoma of BE (sensitivity of $92 \%$ and specificity of $96 \%$, respectively).

\section{Methylene blue and indigo carmine}

Methylene blue selectively stains the specialized intestinal epithelium. Three randomized cross-over trials have shown that the diagnostic accuracy of methylene blue-assisted biopsies is higher than that of stepwise four-quadrant biopsies ('Seattle protocol'). ${ }^{36-38}$ However, a meta-analysis of nine studies determined that methylene blue target biopsies were not superior to random biopsies for the diagnosis of dysplasia. ${ }^{39}$

One of the contrast dyes, indigo carmine, seeps between the grooves and assists in observing the contour of the mucosal surface. It has been shown to be useful for the detection of colon adenomas. However, a randomized crossover study showed that indigo carmine did not increase the BE's dysplasia detection rate compared to high-resolution WLE. ${ }^{40}$

\section{VIRTUAL CHROMOENDOSCOPY}

Virtual chromoendoscopy is a hardware-based technique. In contrast to conventional chromoendoscopy, it is easy to obtain an enhanced image by turning on a button-switch and allowing the colorimetric manipulation of target lesions and is replacing dye-based chromoendoscopy. Virtual chromoendoscopy can be divided into several categories. Light filter technologies using optical filters to adapt to specific wavelengths include narrow-band imaging (NBI), which is the most investigated technique in the IEE field. Software-based digital image processing techniques include flexible spectral imaging color enhancement (FICE) and i-SCAN. The most recently introduced techniques, namely, blue laser imaging (BLI) and light color imaging (LCI) have similar principles in generating an endoscopic image to NBI. However, BLI and LCI use monochromatic lasers instead of xenon light with an optical filter.

\section{NBI, with or without magnification}

\section{a. Esophageal squamous cell dysplasia and carcinoma}

NBI is the most widely studied and used virtual chromoendoscopy. It utilizes two kinds of light via an optical filter: blue light (wavelength of $415 \pm 30 \mathrm{~nm}$ ) and green light (wavelength
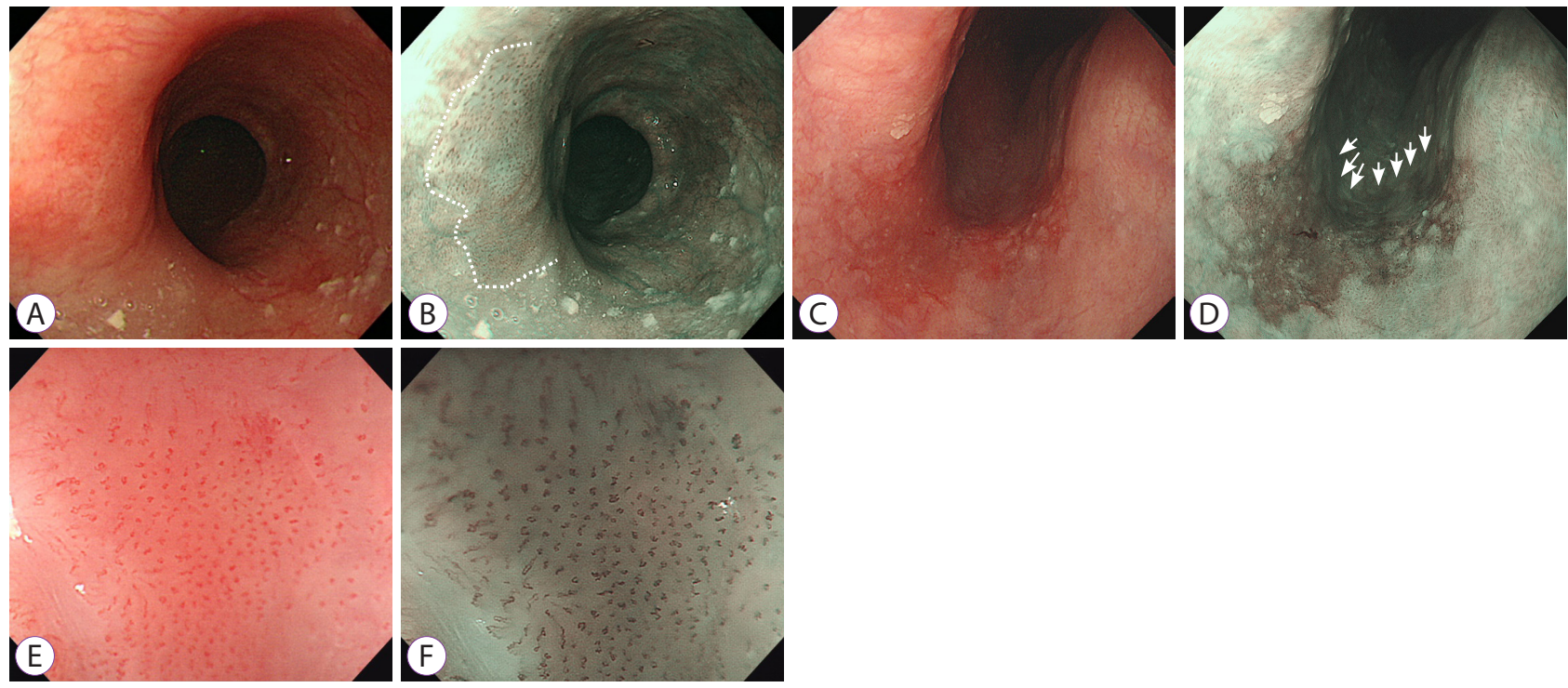

Fig. 2. (A) White light image endoscopy (WLE) shows flat reddish mucosal lesions; however, it is difficult to define the margin of the abnormal mucosa. (B) The tumor margin is more distinct from the background mucosa under narrow-band imaging (NBI) without magnification (white dotted line). This lesion is diagnosed as highgrade intraepithelial neoplasia after endoscopic submucosa dissection. (C) WLE shows a flat reddish mucosal lesion, and it is more delineated than (A); however, it is difficult to define the distal margin. (D) NBI showed the distal margin more definitely than WLE (white arrows). This lesion is diagnosed as squamous cell carcinoma after biopsy. (E) Intrapapillary capillary loop (IPCL) shows red dots under WLE with magnification. (F) IPCL shows brown dots under NBI with magnification (ME-NBI) and the morphological features are more clearly observed under ME-NBI. The caliber of IPCL is prominently increased and the loop-like formation is reserved (IPCL type IV). 
$540 \pm 30 \mathrm{~nm}$ ). The NBI system emphasizes capillary vessels by absorbing hemoglobin in capillaries located on the mucosal surface. Esophageal dysplasia and ESCC are brown in color under NBI (Fig. 2). The diagnostic accuracy of non-magnifying endoscopy with NBI (NM-NBI) for superficial ESCC was significantly higher than that of WLE. ${ }^{15} \mathrm{~A}$ recent meta-analysis including 12 studies with 1,911 patients reported that NBI was suitable for esophageal evaluation to diagnose esophageal squamous cell neoplasm. NBI has been shown to be superior to LCE in the differentiation of neoplastic lesions from other benign mucosal alterations (sensitivity $88 \%$ vs. $92 \%, p>0.05$; specificity $88 \%$ vs. $82 \%, p<0.001) .{ }^{41}$ A prospective comparative study of NM-NBI and LCE in screening early ESCC and HGIN found the accuracy and specificity of NM-NBI were superior to those of LCE (77.0\% vs. $68.0 \%, p=0.03 ; 95.2 \%$ vs. $64.0 \%, p=0.01) .{ }^{42} \mathrm{NM}-\mathrm{NBI}$ could improve the early detection of ESCC; however, it could also yield false-positive results because the non-specific inflammatory lesions may be identified as "brownish area". ${ }^{43} \mathrm{ME}$ can provide magnification of up to $\times 150$. This aids the diagnosis through a detailed examination of microvascular and microsurface features and helps to predict the depth of invasion of early esophageal neoplastic lesions when used with NBI. ${ }^{44} \mathrm{ME}-\mathrm{NBI}$ is presumed to be use- ful and might reduce the false-positive rate of NM-NBI in the diagnosis of superficial ESCC. ${ }^{43}$ In a multicenter, prospective RCT, MN-NBI detected superficial cancers more frequently than WLE in the esophagus (97\% vs. 55\%, $p<0.001) .{ }^{15} \mathrm{~A}$ non-inferiority RCT that compared the diagnostic accuracy of ME-NBI with that of LCE showed no significant difference between the two modalities with respect to the sensitivity and in any other diagnostic accuracy measure for superficial ESCC detection. ${ }^{16}$ Intrapapillary capillary loop (IPCL) patterns, which are well observed with ME-NBI, are useful for the early and accurate diagnosis of esophageal cell neoplasm and prediction of the depth of invasion of ESCC (Fig. 3). The IPCL is an intrapapillary capillary that arises from the fourth branch of the arborescent vessels into the epithelial papillae and forms single loops. IPCL patterns undergo stepwise morphologic changes of "dilation", "tortuosity", "change in caliber" and "various shapes" with the progression of esophageal cell neoplasm (Fig. 4). ${ }^{45}$ Inoue classification and Arima classification were proposed to classify the invasion depth of superficial ESCC based on the change in the microvascular pattern (Figs. $5 \mathrm{~A}, 5 \mathrm{~B}) .^{45-48}$ The overall accuracy of IPCL-IV and IPCL-V was $80 \%$ after analyzing the histological correlation of the IPCL classification in 185 superficial ESCC. ${ }^{46}$ Additionally, the sen-
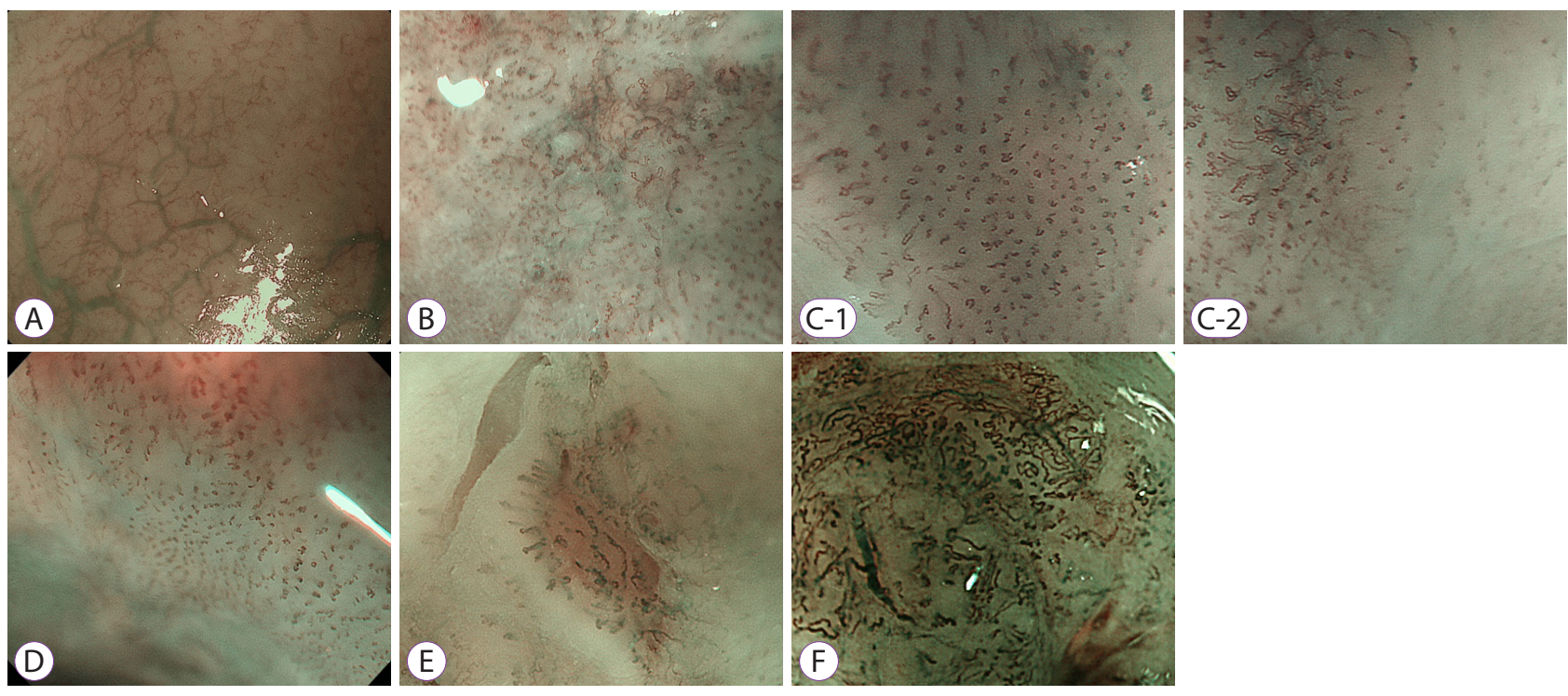

Fig. 3. Various morphologic features of intrapapillary capillary loop (IPCL) in squamous cell neoplasms under narrow-band imaging with magnification. (A) In normal mucosa: thin and regular patterns of IPCL can be observed. (B) The caliber and the density of IPCL is slightly increased and the length of IPCL is also elongated. This lesion was histologically diagnosed as low-grade intraepithelial dysplasia of the esophagus. (C-1) The caliber of the IPCL is prominently increased, and the loop-like formation is reserved. (C-2) The density is prominently increased compared to the background mucosa, and it appears as a brownish island (formation of area). This lesion was histologically diagnosed as a high-grade intraepithelial dysplasia of the esophagus. (D) The caliber of the IPCL is increased irregularly and the arrangement is irregular. This lesion was histologically diagnosed as esophageal high-grade intraepithelial dysplasia with focal squamous cell carcinoma of focally invaded the muscularis mucosae. (E) Tortuous, irregular IPCL was observed, and the arrangement was irregular. The loop-like formation was destroyed. This lesion was histologically diagnosed as esophageal squamous cell carcinoma with focal invasion of the submucosa at a depth of $200 \mu \mathrm{m}$. (F) Highly dilated multiple layered, irregularly branched, and reticular vessels were observed. This indicates a massively invasive submucosal carcinoma. 
Dilation

Tortuosity

Caliber change

Non-uniformity in the appearance $\ln \Omega$

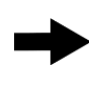

mon
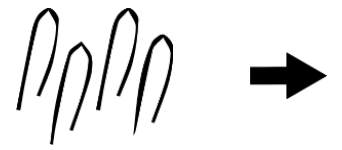

$\{\{\}\{\}\{$

Inlin

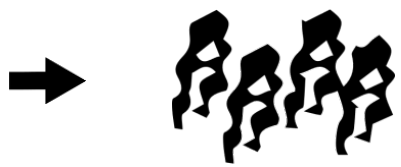

$\beta \beta B \beta$
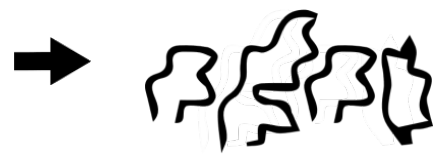

Fig. 4. Intrapapillary capillary loop patterns undergo stepwise morphologic changes of "dilation", "tortuosity", "change in caliber" and "various shapes" with the progression of esophageal squamous cell neoplasm.

sitivity and specificity of ME-NBI to differentiate intramucosal cancer from submucosal cancer was $78 \%$ and $95 \%$, respectively. ${ }^{49}$ Although Inoue and Arima classifications have been used widely in routine clinical practice, the existence of two classifications has caused considerable confusion. ${ }^{50}$ Recently, the Japan Esophageal Society proposed more simplified classification guidelines for ME diagnosis of ESCC (JES classification) based on the vascular architecture (Fig. 5C). The overall accuracy of the JES classification for the prediction of tumor invasion depth of type B micro-vessels was $90.5 \% .^{51}$ One retrospective study showed reliable interobserver agreement of the JES classification $(\mathrm{k}=0.86,95 \%$ confidence interval [CI]: $0.76-0.95) .^{52}$ A retrospective study of 256 superficial ESCC patients who underwent non-magnifying WLE and ME-NBI for the assessment of the invasion depth before ESD showed that the JES classification provided an accurate estimation of the invasion depth in patients who had superficial ESCC with a histopathological diagnosis of the EP/LPM invasion (positive predictive value of $93 \%)^{50}$

In fact, most of these studies were conducted in a tertiary hospital setting with expert endoscopists. Moreover, ME-NBI is still not very popular even in Japan, and it is not currently available in several non-expert settings. However, since early esophageal neoplastic lesions have no prominent symptoms, there is a greater chance of detection during screening or sur- veillance endoscopy in general practice with non-expert settings. One prospective, non-randomized study compared the diagnostic yield of NBI endoscopy for the screening of squamous HGIN between experienced and less experienced physicians. The sensitivity of NBI was significantly higher in experienced physicians than in less experienced physicians (100\% vs. $53 \%$, respectively, $p<0.001$ ). The authors found that the results from trained physicians are not reproducible in non-expert settings. However, the sensitivities improved from $43 \%$ to $60 \%$ after receiving training for NBI diagnosis of esophageal neoplasia at conferences and 2 to 3 months of training for NBI observation. ${ }^{53}$ Recently, a prospective multicenter RCT was conducted to compare the diagnostic characteristics of NBI and LCE involving expert and non-expert centers to screen ESCC in patients with a history or current squamous cell carcinoma in the aerodigestive tract. A total of 334 patients were enrolled, and the specificity was greater with NBI than with LCE in per-patient analysis ( $37.5 \%$ vs. $21.2 \%, p=0.002)$. The authors concluded that NBI was more specific than LCE in the current gastroenterology practice for the detection of early ESCC as previously demonstrated in expert centers. ${ }^{54}$ The education program for non-expert or less experienced endoscopists may prove useful in improving the diagnostic accuracy of NBI during surveillance or screening endoscopy. Recently, NBI with a "dual-focus" mode (DF-NBI) was developed. It 
(A)

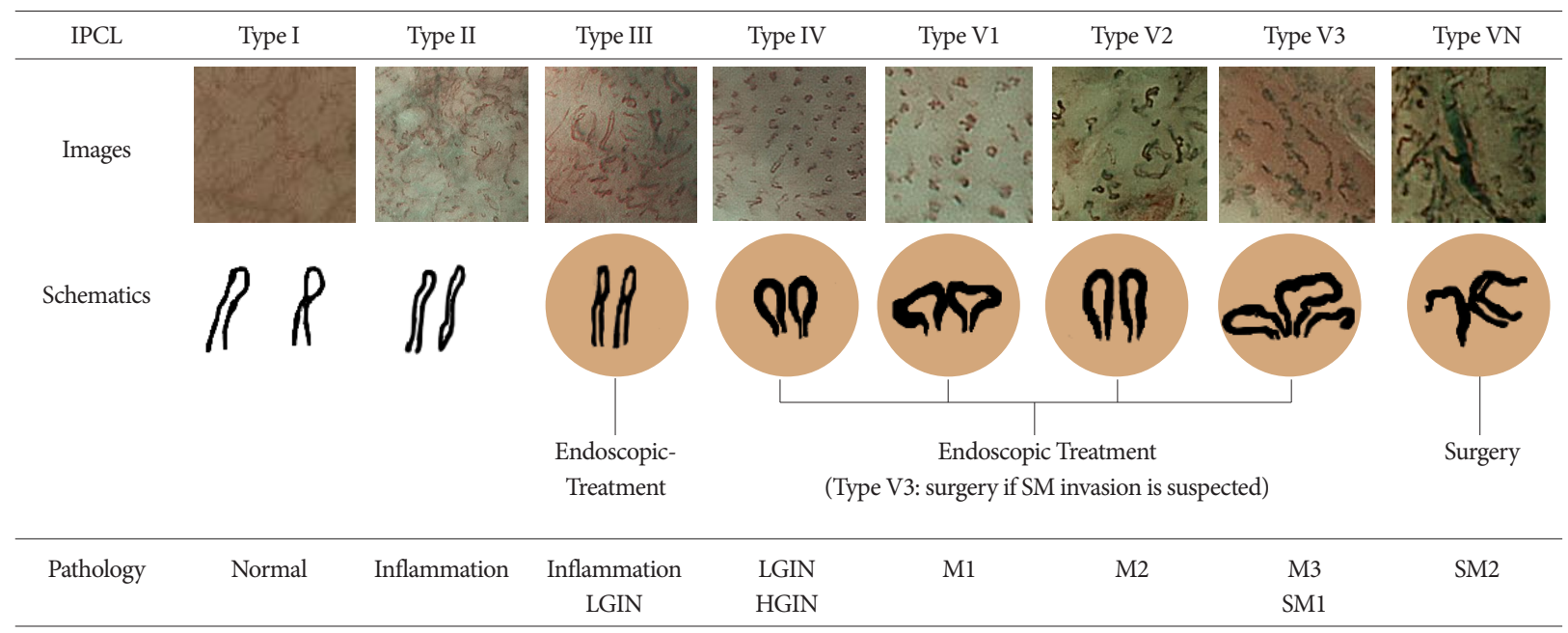

: Formation of area

(B)

(a)
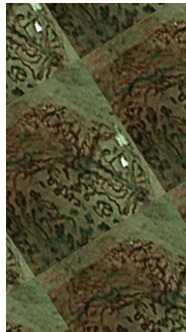

Type 1

(b)

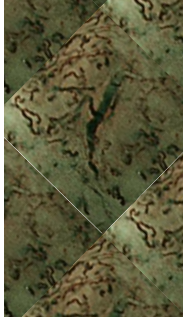

Type 4; multiple layered

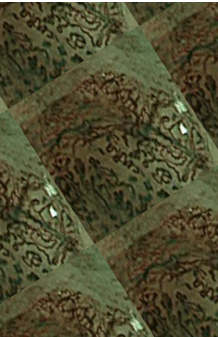

Type 2
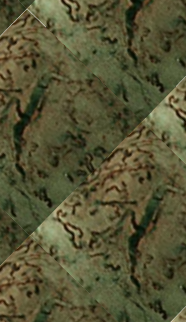

Type 4; irregular branched

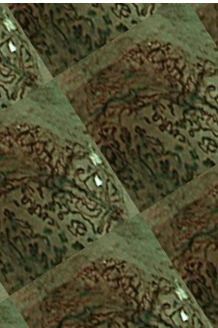

Type 3
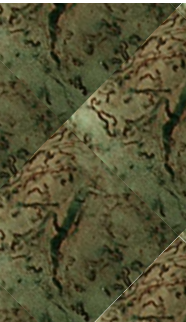

Type 4; reticular

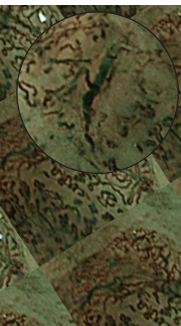

Type 4
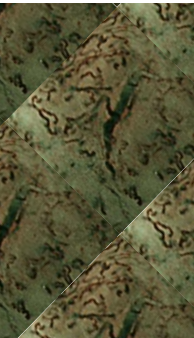

Type 4; avascular area

Fig. 5. Classification systems for esophageal squamous cell neoplasm with magnifying narrow-band imaging.

(A) Inoue classification. ${ }^{45-47}$ Type I IPCL pattern is observed in the normal esophageal mucosa. The elongation and dilation of capillaries are observed in the Type II IPCL. This pattern may indicate esophagitis or reactive changes. Type III IPCL pattern is observed in the "borderline lesions between benign and malignant tumors. Increased vessel caliber and elongation of the IPCL toward the epithelial surface are two important factors in Type IV IPCL pattern. This pattern is observed in a borderline lesion to definite carcinoma. Type V IPCL pattern is divided into four subtypes. Type V1 pattern corresponds to carcinoma in situ (M1) with four characteristic morphological changes: dilation, tortuosity, irregular caliber, and non-uniformity between each IPCL. Type V2 pattern corresponds to the invasion of the lamina propria mucosae (M2) and adds to the features of Type V1 with an elongation of the vessel in the vertical plane. In Type V3, the abnormal vessel spreads in a horizontal plane or extends toward the deeper mucosal layer while losing its loop arrangement. It corresponds to cancer invasion reaching the muscularis mucosa or even to the submucosa. In Type VN pattern, the vessel diameter is approximately three times that of Type V3. This corresponds to a massively invasive submucosal carcinoma. Since there is an extremely low risk of lymph node (LN) metastasis, superficial esophageal squamous cell carcinoma limited to the epithelium or the lamina propria mucosae is absolutely indicated for endoscopic treatment. Endoscopic treatment is indicated for a tumor invading the muscularis mucosa or the submucosa to a depth of $200 \mu \mathrm{m}$ or less from the muscularis mucosae because the rate of LN metastasis is $10 \%-15 \%$. Tumors invading the submucosa to a depth of more than $200 \mu \mathrm{m}$ should be treated with surgery or definitive chemoradiotherapy because the rate of $L N$ metastasis is $30 \%-50 \%$.

(B) Arima classification. ${ }^{48}$ (a) Schematic drawing of microvascular patterns of superficial esophageal lesions. Type 1. Thin, linear capillaries in the subepithelial papilla are observed. This is similar to the normal mucosa. Type 2. Distended and dilated vessels with variations are observed. The structure of capillaries in the subepithelial papilla is preserved and shows a relatively regular arrangement. It is usually observed in inflammatory lesions. Type 3 . Irregular arrangement of destructed vessels in the subepithelial papilla, spiral vessels with an irregular caliber, and crushed vessels are observed. It can be observed in $\mathrm{m} 1$ or $\mathrm{m} 2$ cancers. Type 4 . Irregularly multilayered, irregularly branched, and reticular vessels are observed. Multilayered type 4 vessels appear in tumors with deep m2 invasion. (b) Schematic drawing of subtypes of type 4 vessels. 


\begin{tabular}{|c|c|c|c|c|c|}
\hline Vessel type & Schematics & Images & Definitions & Depth of invasion & Histology \\
\hline Type A & $\&$ & & $\begin{array}{l}\text { Normal IPCL or abnormal microvessels without severe } \\
\text { irregularitya (three or fewer factors) } \\
\text { (vessel caliber }=7-10 \mu \mathrm{m} \text { ) }\end{array}$ & No invasion & $\begin{array}{l}\text { Normal epithelium } \\
\text { Inflammation } \\
\text { LGIN }\end{array}$ \\
\hline Type B & & & $\begin{array}{l}\text { Abnormal microvessels with severe irregularity or highly } \\
\text { dilated abnormal vessels }{ }^{\text {a) }} \text { (fulfill all of four morphological } \\
\text { factors) }\end{array}$ & & \\
\hline B1 & & & $\begin{array}{l}\text { Type } B \text { vessels }+ \text { a loop-like formation } \\
\text { (vessel caliber }=\text { around } 20 \mu \mathrm{m})\end{array}$ & T1a (EP or LPM) & \\
\hline B2 & & & Type B vessels + loss of loop-like formation & Tla (MM) or T1b (SM1) & $\begin{array}{l}\text { HGIN } \\
\text { Invasive SCC }\end{array}$ \\
\hline B3 & & & $\begin{array}{l}\text { Highly dilated vessels (calibers appears to be more than } \\
\text { three times that of usual Type B2 vessels (vessel caliber > } \\
60 \mu \mathrm{m} \text { ) }\end{array}$ & T1b (SM2) or deeper & \\
\hline
\end{tabular}

${ }^{\text {a) }}$ Four morphological factors represent microvascular irregularity: tortuosity, dilation, irregular caliber, various shape

Fig. 5. Continued. (C) JES classification for narrow-band imaging with magnifying endoscopy. ${ }^{51} \mathrm{EP}$, epithelium; HGIN, high-grade intraepithelial neoplasia; IPCL, intrapapillary capillary loop; JES, Japan Esophageal Society; LGIN, low-grade intraepithelial neoplasia; LPM lamina propria mucosae; MM, muscularis mucosae; SCC, squamous cell carinoma; SM, submucosa.

is more distributed and used than ME-NBI and may provide easier magnification than conventional ME-NBI. ${ }^{55}$ A prospective controlled non-inferiority trial for superficial ESCC in the pharynx and esophagus showed that the detection rate of DFNBI was not inferior to that of ME-NBI. ${ }^{56}$ It might be thought that DF-NBI could be used as an alternative to conventional ME-NBI; however, additional studies are needed to support the usefulness of DF-NBI.

\section{b. Barrett's esophagus and associated dysplasia and adenocarcinoma}

$\mathrm{BE}$ is the proven precursor of EAC. ${ }^{7}$ One multicenter prospective study that examined 783 patients found that EAC was diagnosed at an earlier stage during $\mathrm{BE}$ surveillance than in the general population $(p<0.001){ }^{57}$ The current gold standard for the diagnosis of BE remains histology. Targeted biopsies from abnormalities as well as the Seattle protocol are recommended for the detection of invisible HGIN or early EAC. Dysplasia in BE can be focal and easily missed; several studies reported that standard WLE might not reliably reveal early neoplasia in $\mathrm{BE}$ and some have shown that random biopsies under WLE might sample only $4 \%$ to $5 \%$ of BE's epithelium. ${ }^{58}$ NBI has been applied in BE for improving the targeting of intestinal metaplasia and dysplasia. The American Society for Gastrointestinal Endoscopy Technology Committee concluded that advanced imaging modalities could be used to guide biopsies and replace random biopsies to detect dysplasia of $\mathrm{BE}$ for trained physicians. ${ }^{59} \mathrm{~A}$ well-designed international RCT showed that NBI targeted biopsies can have the same BE detection rate of high-definition WLE (HD-WLE) examination with the Seattle protocol while requiring fewer biopsies (3.6 vs. $7.6, p<0.0001$ ). Additionally, NBI-targeted biopsies can detect additional areas with dysplasia than biopsies under HD-WLE ( $30 \%$ vs. $21 \%, p=0.01){ }^{60} \mathrm{~A}$ meta-analysis showed that advanced imaging modalities including chromoendoscopy and virtual chromoendoscopy significantly increased the diagnostic yield by $34 \%$ detection dysplasia or cancer in patients with BE $(95 \%$ CI, 20\%-56\%; $p<0.0001){ }^{61}$

Three NBI classification systems for BE have been proposed. ${ }^{62-64}$ They classified the lesions as normal, intestinal metaplasia, and dysplasia by the changes in mucosal and vascular patterns from the NBI image of BE (Table 1). A prospective validation study of these three classification systems showed that the accuracy for non-dysplastic BE identification ranged between 57\% (Kansas and Nottingham) and 63\% (Amsterdam). The accuracy for dysplastic BE was $75 \%$, regardless of the classification system and assessor expertise level. The interobserver agreement ranges from fair (Nottingham, $\kappa=0.34$ ) to moderate (Amsterdam and Kansas, $\kappa=0.47$ and 0.44 respectively). ${ }^{65}$ The Barrett's International NBI group (BING) proposed a more simplified classification using DF-NBI to discriminate neoplastic BE from non-neoplasia. The overall 
Table 1. Classification Systems for Barrett's Esophagus with Image-Enhanced Endoscopy

\begin{tabular}{|c|c|c|c|c|c|}
\hline & Modality & Normal & Intestinal metaplasia & Dysplasia & \\
\hline Kansas $^{62}$ & ME-NBI & $\begin{array}{l}\text { - Circular mucosal pat- } \\
\text { tern } \\
\cdot \text { Normal vascular pattern }\end{array}$ & $\begin{array}{l}\text { - Ridged/villous mucosal } \\
\text { pattern } \\
\text { - Normal vascular pattern }\end{array}$ & $\begin{array}{l}\text { - Irregular distorted mu- } \\
\text { cosal pattern } \\
\text { - Abnormal vascular } \\
\text { pattern }\end{array}$ & $\begin{array}{l}\text { Sensitivity for HGIN 96\% } \\
\text { Specificity for HGIN } 94.4 \% \\
\text { Accuracy for HGIN } 95.2 \%\end{array}$ \\
\hline Amsterdam $^{63}$ & ME-NBI & $\begin{array}{l}\text { - Regular mucosal pattern } \\
\text { - Regular vascular pattern } \\
\text { - Absence of abnormal } \\
\text { blood vessel }\end{array}$ & $\begin{array}{l}\text { - Regular mucosal pattern } \\
\text { - Regular vascular pattern } \\
\text { (villous/gyrus) } \\
\text { - Absence of abnormal } \\
\text { blood vessels }\end{array}$ & $\begin{array}{l}\text { - Irregular mucosal pat- } \\
\text { tern } \\
\text { - Irregular vascular pat- } \\
\text { tern } \\
\text { - Present of abnormal } \\
\text { blood vessels }\end{array}$ & $\begin{array}{l}\text { Sensitivity for HGIN 94\% } \\
\text { Specificity for HGIN 76\% } \\
\text { PPV for HGIN 64\% } \\
\text { NPV for HGIN 98\% }\end{array}$ \\
\hline Nottingham $^{64}$ & ME-NBI & $\begin{array}{l}\text { - Type A: round/oval pits } \\
\text { with regular microvas- } \\
\text { culature }\end{array}$ & $\begin{array}{l}\text { - Type B: villous/ridge/ } \\
\text { linear pits with regular } \\
\text { microvasculature } \\
\text { - Type C: absent pits with } \\
\text { regular microvascula- } \\
\text { ture }\end{array}$ & $\begin{array}{l}\text { - Type D: distorted pits } \\
\text { with irregular microvas- } \\
\text { culature }\end{array}$ & $\begin{array}{l}\text { PPV for HGIN } 81 \% \\
\text { NPV for HGIN 99\% }\end{array}$ \\
\hline $\begin{array}{l}\text { Barrett's inter- } \\
\text { national NBI } \\
\text { group (BING) } \\
\text { criteria }^{58}\end{array}$ & $\begin{array}{l}\text { NBI with } \\
\text { "near } \\
\text { focus" } \\
\text { mode }\end{array}$ & $\begin{array}{l}\text { - Mucosal pattern: cir- } \\
\text { cular, ridged/villous or } \\
\text { tubular } \\
\text { - Vascular pattern: blood } \\
\text { vessels situated regularly } \\
\text { along or between muco- } \\
\text { sal ridges and/or those } \\
\text { showing normal, long, } \\
\text { branching patterns }\end{array}$ & & $\begin{array}{l}\text { - Mucosal pattern: absent } \\
\text { or irregular patterns } \\
\text { - Vascular pattern: focally } \\
\text { or diffusely distributed } \\
\text { vessels no following nor- } \\
\text { mal architecture of the } \\
\text { mucosa }\end{array}$ & $\begin{array}{l}\text { Overall sensitivity } 80 \% \\
\text { Overall specificity } 88 \% \\
\text { Overall accuracy } 85 \% \\
\text { Overall PPV } 81 \% \\
\text { Overall NPV } 88 \%\end{array}$ \\
\hline $\begin{array}{l}\text { Blue light imag- } \\
\text { ing for Barrett's } \\
\text { neoplasia } \\
\text { classification } \\
(\text { BLINC) })^{83}\end{array}$ & BLI & $\begin{array}{l}\text { - Mucosal pits: circular \& } \\
\text { tubular type, uniform } \\
\text { distribution, normal } \\
\text { density } \\
\text { - Vessel: non dilated type, } \\
\text { pericryptal distribution, } \\
\text { normal density } \\
\text { - Color: no focal darkness }\end{array}$ & & $\begin{array}{l}\text { - Mucosal pits: amor- } \\
\text { phous type, focal loss } \\
\text { distribution, increase } \\
\text { density } \\
\text { - Vessels: dilated \& tor- } \\
\text { tuous type, non-cryptal } \\
\text { distribution, increased } \\
\text { (new vessels) density } \\
\text { - Color: dark }\end{array}$ & $\begin{array}{l}\text { Overall sensitivity } 96 \% \\
\text { Overall specificity } 94.4 \% \\
\text { Overall accuracy } 95.2 \%\end{array}$ \\
\hline
\end{tabular}

BLI, blue laser image; HGIN, high-grade intraepithelial neoplasia; ME-NBI, magnifying endoscopy with narrow-band imaging; NBI, narrow-band imaging; NPV, negative predictive value; PPV, positive predictive value.

accuracy, sensitivity, and specificity of the BING criteria for identifying BE dysplasia were $85 \%, 80 \%$, and $88 \%$, respectively. The interobserver agreement was also good $(\kappa=0.68)$ (Table $1) .^{58}$ However, the BING criteria showed a lower accuracy rate when it was adapted with different modalities (i-SCAN, magnification, and/or AA). ${ }^{66}$

\section{i-SCAN, FICE, BLI, and LCI}

\section{i-SCAN and FICE}

i-SCAN and FICE are IEEs using post-processing imaging technology. FICE enhances the mucosal surface contrast and makes the vascular pattern prominent without spraying dye. ${ }^{67}$ The transnasal FICE allows for clear visualization of palisade vessels and provides better contrasting images of the demarcation between the BE mucosa and the gastric mucosa. ${ }^{68} \mathrm{~A}$ RCT of 57 patients with BE and a history of HGIN/early EAC or suspected HGIN/early EAC reported that the sensitivity of FICE for targeted biopsies of HGIN/early EAC is similar with AA chromoendoscopy ('per lesion' basis, $87 \%$ ). ${ }^{69}$ The color difference between ESCC and the background mucosa is higher with FICE than WLI; however, IPCL patterns are not clearly visualized compared with NBI observation. ${ }^{70}$ FICE and ME-FICE were compared with LCE and ME-LCE, respective- 
ly, for the assessment of the diagnostic ability of early ESCC and precancerous lesions in 257 patients; the sensitivity of FICE and ME-FICE to detect early ESCC was better than that of LCE and ME-LCE. However, there was no statistical significance $(92.6 \%$ vs. $88.9 \%, p>0.05 ; 96.3 \%$ vs. $92.6 \%, p>0.05$, respectively). ${ }^{71}$

i-SCAN is a technology that post-processes endoscopic imaging to provide surface, contrast, and tone enhancement. ${ }^{72}$ It has been shown to be superior to WLE in the detection of $\mathrm{BE}^{73}$ In one RCT, i-SCAN or AA-guided biopsies had a significantly higher diagnostic yield for detecting $\mathrm{BE}$ and even required fewer specimens as compared to biopsies with a Seatthe protocol ( $66 \%$ vs. $21 \%$ for i-SCAN target biopsy vs. random biopsies). ${ }^{74}$

\section{BLI and LCI}

BLI uses two different lasers, $410 \mathrm{~nm}$ (blue violet) and 450 $\mathrm{nm}$ (blue) as light sources. Shorter wavelength lasers contribute to informing the mucosal microvasculature, such as NBI, and longer wavelength lasers produce WLE by fluorescence stimulation. There are four observation modes in the BLI system: WLE, LCI, BLI-bright, and BLI-contrast. BLI without ME produces a higher color contrast between the lesion and the background area, and subsequently clearly shows the boundaries of esophageal cancer (Fig. 6). Similar to NBI, IPCL patterns are visualized in the brown area. ${ }^{70}$

\section{a. Esophageal squamous cell dysplasia and carcinoma}

A single-center prospective study showed the diagnosis rate of BLI for early ESCC was similar to that of NBI ( $85.7 \%$ vs. $87.5 \%)$ and slightly lower than that of LCE (85.7\% vs. $91.3 \%)$; however, there was no significant difference $(p>0.05){ }^{75}$ BLIbright, a brighter BLI, is useful for the endoscopic observation for a distant view by showing a well-demarcated brownish area. A retrospective analysis of 25 superficial ESCC showed BLI-bright more efficaciously recognizing superficial ESCC than WLE, NBI, and FICE in a distant view. ${ }^{76}$ LCI may improve the endoscopic diagnosis of the invasion depth of superficial ESCC. LCI can make the red areas redder because LCI guarantees the simultaneous expansion and reduction of color information. Thus, esophageal neoplasms can be detected more easily using color differences. A recent study of LCI with

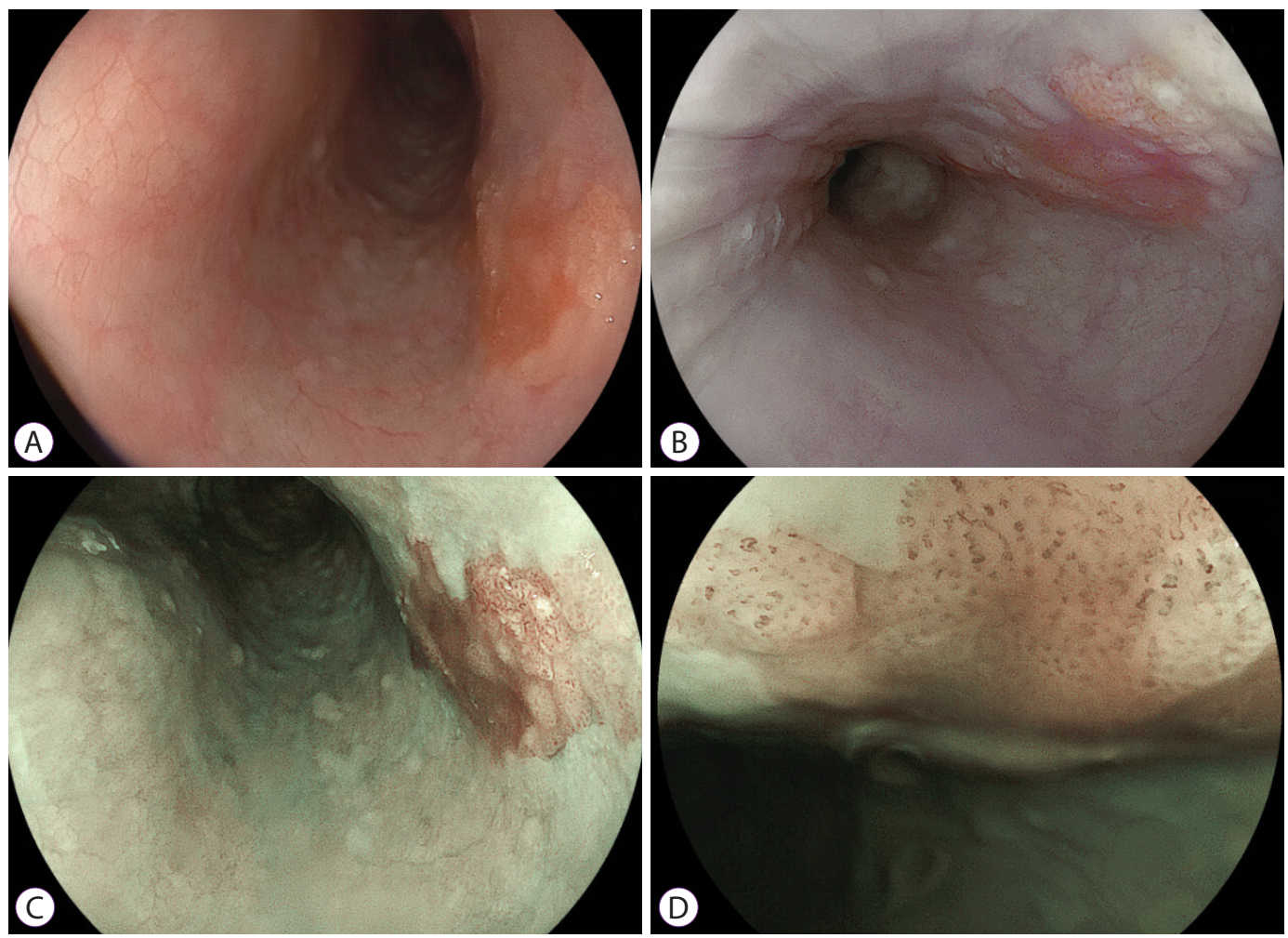

Fig. 6. Blue laser image (BLI) and linked color image (LCI) of esophageal squamous cell carcinoma. (A) A flat reddish lesion was observed under white-light endoscopy. (B) The lesion was observed to be of purple color with $\mathrm{LCl}$. (C) The lesion was observed with brown color with BLI. (D) Intrapapillary capillary loops were observed under BLI with magnification and it is similar with narrow-band image with magnification. 
observation of 52 lesions in the diagnosis of superficial ESCC found that the color difference between the normal mucosa and superficial ESCC was larger in the muscularis mucosae/ upper third of the submucosa or deeper group than in the EP/ LPM group $(p=0.025))^{77} \mathrm{~A}$ recent retrospective study of 46 superficial ESCC lesions showed almost the same results as BLIbright; LCI improves the superficial ESCC visibility compared with WLE and is useful for cases with multiple Lugol-voiding areas; and the interobserver agreement was substantial (37\% improved with LCI, $\kappa=0.74 ; 39 \%$ improved BLI-bring, $\kappa=0.60)$. The color difference between the lesion and background mucosa was significantly higher in LCI then in WLE $(20.8 \pm 7.9 \text { vs. } 9.2 \pm 6.1, p<0.05)^{78}$

\section{b. Barrett's esophagus and associated dysplasia and adenocarcinoma}

The extent of BE is easily observed using BLI and LCI through a high color contrast with the gastric mucosa. An international multicenter cohort study found that BLI has an additional value to WLE in the visualization and delineation of early BE neoplasia. ${ }^{79} \mathrm{~A}$ study about the efficacy of LCI in the diagnosis of $\mathrm{BE}$ including a long-segment $\mathrm{BE}$ and early EAC using color values and color differences have shown that LCI advances the visibility of $\mathrm{BE}$ and $\mathrm{EAC}$ and may improve the detection rate of these lesions compared with the WLE and BLI-bright mode. ${ }^{80}$ Additionally, LCI improved the visibility of short-segment BE compared with WLE, especially for trainees, when evaluated both subjectively and objectively. ${ }^{81} \mathrm{~A}$ cohort study prospectively collected 30 neoplastic BE images captured with WLE, BLI, and LCI reported that the use of BLI and LCI has a significant additional value for the visualization of BE's neoplasia when used by non-expert endoscopists. ${ }^{82} \mathrm{~A}$ new classification system using BLI (BLINC) was proposed for the optimal diagnosis of BE's neoplasia, and BLINC classification has the potential to improve the optical diagnosis of BE's neoplasia with a high degree of sensitivity (96\%) and interobserver agreement $(\kappa>0.8){ }^{83}$

\section{CURRENT STATUS OF ARTIFICIAL INTELLIGENCE IN IEE FIELD FOR IDENTIFICATION OF ESOPHAGEAL NEOPLASIA}

Artificial intelligence (AI) has shown promising data for the identification of the neoplastic lesions of the gastrointestinal tract. Although IEEs have provided a desirable diagnostic value, the diagnosis of esophageal cancer relies on the expertise of the individual physician; also, there may be interobserver vari- ability. Moreover, processing a large dataset can take time. AI may reduce the interobserver variability and shorten the time required for endoscopic evaluation. The AI could be used as a cutting-edge deep learning technique to detect early esophageal cancers.

A recent study on AI with deep neural networks using NBI/ BLI/WLE images with or without magnification with training image data showed a high sensitivity for detecting ESCC by non-ME and high accuracy for differentiating ESCC from non-cancerous lesions by ME. There was no significant difference in the diagnostic performance between the AI system and the experienced endoscopists. ${ }^{84}$ Another study of the AI system showed significantly higher sensitivity (91\% vs. $79 \%$ ) for detecting ESCC and higher accuracy (63\% vs. $75 \%$ ) for characterizing ESCC from the non-cancerous tissue when compared to endoscopic experts. ${ }^{85}$ Moreover, another study with AI using deep learning showed high sensitivity and specificity in the detection of pre-cancerous and early ESCC lesions, especially for junior endoscopists. ${ }^{86}$ A proof-of-concept study using computer-aided endoscopic diagnosis using convolutional neural networks $(\mathrm{CNN})$, differentiated abnormal from normal IPCL patterns with $93.7 \%$ accuracy, $89.3 \%$ sensitivity, and $98.0 \%$ specificity for classifying abnormal IPCL patterns. Moreover, it operated in real-time with a diagnostic prediction time between $26.17 \mathrm{~ms}$ and $37.48 \mathrm{~ms} .{ }^{87}$ Furthermore, the AI system is effective in evaluating the invasion depth of superficial ESCC in video images, and it is comparable or even better than expert endoscopists (accuracies of $87.3 \%$ and $89.2 \%$ for NM-NBI and ME-NBI, respectively). ${ }^{88}$

$\mathrm{AI}$ also helps to identify early neoplasia in $\mathrm{BE} \cdot{ }^{89-91}$ One pilot study that analyzed 458 test images (225 dysplasia and 233 non-dysplasia) with a CNN algorithm showed that AI was able to detect early esophageal neoplasia in BE images with high accuracy of $95.4 \%{ }^{91}$ A recent study of the video-based computer-assisted algorithm system for the detection of BE neoplasia reported an accuracy of $83 \%$ (95\% CI, $78 \%-89 \%$ ), a sensitivity of $85 \%$ (95\% CI, 76\%-98\%), and a specificity of $83 \%(95 \%$ CI, $76 \%-90 \%){ }^{92}$

\section{CONCLUSIONS}

IEE is better and faster in diagnosing and predicting the depth of invasion of esophageal malignant or pre-malignant lesions than conventional WLE before invasive histological diagnosis. However, the results rely on the experience and expertise of the endoscopist. This is one of the tasks to be overcome. It is thought that this can be overcome through the advances in AI technology along with the efforts of the physicians, including education and training of IEE. 
Conflicts of Interest

The authors have no potential conflicts of interest.

Funding None.

Author Contributions

Writing-original draft: Shin Hee Kim

Writing-review\&editing: SHK, Su Jin Hong

ORCID

Shin Hee Kim:

Su Jin Hong:

https://orcid.org/0000-0001-9054-3276

https://orcid.org/0000-0003-2012-0360

\section{REFERENCES}

1. Bray F, Ferlay J, Soerjomataram I, Siegel RL, Torre LA, Jemal A. Global cancer statistics 2018: GLOBOCAN estimates of incidence and mortality worldwide for 36 cancers in 185 countries. CA Cancer J Clin 2018;68:394-424.

2. Arnold M, Soerjomataram I, Ferlay J, Forman D. Global incidence of oesophageal cancer by histological subtype in 2012. Gut 2015;64:381387.

3. Simard EP, Ward EM, Siegel R, Jemal A. Cancers with increasing incidence trends in the United States: 1999 through 2008. CA Cancer J Clin 2012;62:118-128.

4. Pennathur A, Gibson MK, Jobe BA, Luketich JD. Oesophageal carcinoma. Lancet 2013;381:400-412.

5. Arnold M, Laversanne M, Brown LM, Devesa SS, Bray F. Predicting the future burden of esophageal cancer by histological subtype: international trends in incidence up to 2030. Am J Gastroenterol 2017;112:1247-1255.

6. Wong A, Fitzgerald RC. Epidemiologic risk factors for Barrett's esophagus and associated adenocarcinoma. Clin Gastroenterol Hepatol 2005;3:1-10.

7. Maitra I, Date RS, Martin FL. Towards screening Barrett's oesophagus: current guidelines, imaging modalities and future developments. Clin J Gastroenterol 2020;13:635-649.

8. Gupta B, Kumar N. Worldwide incidence, mortality and time trends for cancer of the oesophagus. Eur J Cancer Prev 2017;26:107-118.

9. Nuytens F, Dabakuyo-Yonli TS, Meunier B, et al. Five-year survival outcomes of hybrid minimally invasive esophagectomy in esophageal cancer: results of the miro randomized clinical trial. JAMA Surg 2021;156:323-332.

10. Enzinger PC, Mayer RJ. Esophageal cancer. N Engl J Med 2003;349:22412252.

11. Huh CW, Jung DH, Kim JH, Ma DW, Youn YH, Park H. Clinical implication of endoscopic gross appearance in superficial esophageal squamous carcinoma: revisited. Surg Endosc 2018;32:367-375.

12. Higuchi K, Tanabe S, Koizumi W, et al. Expansion of the indications for endoscopic mucosal resection in patients with superficial esophageal carcinoma. Endoscopy 2007;39:36-40.

13. Choi JY, Park YS, Jung HY, et al. Feasibility of endoscopic resection in superficial esophageal squamous carcinoma. Gastrointest Endosc 2011;73:881-889, 889.e1- e2.

14. Nishizawa T, Suzuki H. Long-term outcomes of endoscopic submucosal dissection for superficial esophageal squamous cell carcinoma. Cancers 2020;12:E2849.

15. Muto M, Minashi K, Yano T, et al. Early detection of superficial squamous cell carcinoma in the head and neck region and esophagus by narrow band imaging: a multicenter randomized controlled trial. J Clin
Oncol 2010;28:1566-1572.

16. Goda K, Dobashi A, Yoshimura N, et al. Narrow-band imaging magnifying endoscopy versus lugol chromoendoscopy with pink-color sign assessment in the diagnosis of superficial esophageal squamous neoplasms: a randomised noninferiority trial. Gastroenterol Res Pract 2015;2015:639462.

17. Hoffman A, Manner H, Rey JW, Kiesslich R. A guide to multimodal endoscopy imaging for gastrointestinal malignancy - an early indicator. Nat Rev Gastroenterol Hepatol 2017;14:421-434.

18. Mori M, Adachi Y, Matsushima T, Matsuda H, Kuwano H, Sugimachi K. Lugol staining pattern and histology of esophageal lesions. Am J Gastroenterol 1993;88:701-705.

19. Pimentel-Nunes P, Dinis-Ribeiro M, Ponchon T, et al. Endoscopic submucosal dissection: european society of gastrointestinal endoscopy (ESGE) guideline. Endoscopy 2015;47:829-854.

20. Hashimoto CL, Iriya K, Baba ER, et al. Lugol's dye spray chromoendoscopy establishes early diagnosis of esophageal cancer in patients with primary head and neck cancer. Am J Gastroenterol 2005;100:275-282.

21. Toriie S, Akasaka Y, Yamaguchi K, et al. New trial for endoscopical observation of esophagus by dye spraying method. G E N 1976;30:159-165.

22. Shiozaki H, Tahara H, Kobayashi K, et al. Endoscopic screening of early esophageal cancer with the Lugol dye method in patients with head and neck cancers. Cancer 1990;66:2068-2071.

23. Ina $\mathrm{H}$, Shibuya $\mathrm{H}$, Ohashi I, Kitagawa $\mathrm{M}$. The frequency of a concomitant early esophageal cancer in male patients with oral and oropharyngeal cancer. Screening results using Lugol dye endoscopy. Cancer 1994;73:2038-2041.

24. Meyer V, Burtin P, Bour B, et al. Endoscopic detection of early esophageal cancer in a high-risk population: does Lugol staining improve videoendoscopy? Gastrointest Endosc 1997;45:480-484.

25. Shimizu Y, Omori T, Yokoyama A, et al. Endoscopic diagnosis of early squamous neoplasia of the esophagus with iodine staining: high-grade intra-epithelial neoplasia turns pink within a few minutes. J Gastroenterol Hepatol 2008;23:546-550.

26. Kondo H, Fukuda H, Ono H, et al. Sodium thiosulfate solution spray for relief of irritation caused by Lugol's stain in chromoendoscopy. Gastrointest Endosc 2001;53:199-202.

27. Dubuc J, Legoux J-L, Winnock M, et al. Endoscopic screening for esophageal squamous-cell carcinoma in high-risk patients: a prospective study conducted in 62 French endoscopy centers. Endoscopy 2006;38:690695.

28. Pech O. Lugol staining for early esophageal neoplasia: less is sometimes more. Gastrointest Endosc 2020;91:771-772.

29. Gotoda T, Kanzaki H, Okamoto Y, et al. Tolerability and efficacy of the concentration of iodine solution during esophageal chromoendoscopy: a double-blind randomized controlled trial. Gastrointest Endosc 2020;91:763-770.

30. Longcroft-Wheaton G, Brown J, Basford P, Cowlishaw D, Higgins B, Bhandari P. Duration of acetowhitening as a novel objective tool for diagnosing high risk neoplasia in Barrett's esophagus: a prospective cohort trial. Endoscopy 2013;45:426-432.

31. Longcroft-Wheaton G, Duku M, Mead R, Poller D, Bhandari P. Acetic acid spray is an effective tool for the endoscopic detection of neoplasia in patients with Barrett's esophagus. Clin Gastroenterol Hepatol 2010;8:843-847.

32. Pohl J, Pech O, May A, Manner H, Fissler-Eckhoff A, Ell C. Incidence of macroscopically occult neoplasias in Barrett's esophagus: are random biopsies dispensable in the era of advanced endoscopic imaging? Am J Gastroenterol 2010;105:2350-2356.

33. Tholoor S, Bhattacharyya R, Tsagkournis O, Longcroft-Wheaton G, Bhandari P. Acetic acid chromoendoscopy in Barrett's esophagus surveillance is superior to the standardized random biopsy protocol: results from a large cohort study (with video). Gastrointest Endosc 2014;80:417424 . 
34. Coletta M, Sami SS, Nachiappan A, Fraquelli M, Casazza G, Ragunath K. Acetic acid chromoendoscopy for the diagnosis of early neoplasia and specialized intestinal metaplasia in Barrett's esophagus: a meta-analysis. Gastrointest Endosc 2016;83:57-67.e1.

35. ASGE Technology Committee, Thosani N, Abu Dayyeh BK, et al. ASGE technology committee systematic review and meta-analysis assessing the ASGE preservation and incorporation of valuable endoscopic innovations thresholds for adopting real-time imaging-assisted endoscopic targeted biopsy during endoscopic surveillance of Barrett's esophagus. Gastrointest Endosc 2016;83:684-698.e7.

36. Canto MI, Setrakian S, Willis J, et al. Methylene blue-directed biopsies improve detection of intestinal metaplasia and dysplasia in Barrett's esophagus. Gastrointest Endosc 2000;51:560-568.

37. Wo JM, Ray MB, Mayfield-Stokes S, et al. Comparison of methylene blue-directed biopsies and conventional biopsies in the detection of intestinal metaplasia and dysplasia in Barrett's esophagus: a preliminary study. Gastrointest Endosc 2001;54:294-301.

38. Ragunath K, Krasner N, Raman VS, Haqqani MT, Cheung WY. A randomized, prospective cross-over trial comparing methylene blue-directed biopsy and conventional random biopsy for detecting intestinal metaplasia and dysplasia in Barrett's esophagus. Endoscopy 2003;35:9981003.

39. Ngamruengphong S, Sharma VK, Das A. Diagnostic yield of methylene blue chromoendoscopy for detecting specialized intestinal metaplasia and dysplasia in Barrett's esophagus: a meta-analysis. Gastrointest Endosc 2009;69:1021-1028.

40. Kara MA, Peters FP, Rosmolen WD, et al. High-resolution endoscopy plus chromoendoscopy or narrow-band imaging in Barrett's esophagus: a prospective randomized crossover study. Endoscopy 2005;37:929-936.

41. Morita FHA, Bernardo WM, Ide E, et al. Narrow band imaging versus lugol chromoendoscopy to diagnose squamous cell carcinoma of the esophagus: a systematic review and meta-analysis. BMC Cancer 2017;17:54.

42. Nagami $Y$, Tominaga K, Machida $H$, et al. Usefulness of non-magnifying narrow-band imaging in screening of early esophageal squamous cell carcinoma: a prospective comparative study using propensity score matching. Am J Gastroenterol 2014;109:845-854

43. Lee CT, Chang CY, Lee YC, et al. Narrow-band imaging with magnifying endoscopy for the screening of esophageal cancer in patients with primary head and neck cancers. Endoscopy 2010;42:613-619.

44. Ishihara $\mathrm{R}$, Tanaka $\mathrm{H}$, Iishi $\mathrm{H}$, et al. Long-term outcome of esophageal mucosal squamous cell carcinoma without lymphovascular involvement after endoscopic resection. Cancer 2008;112:2166-2172.

45. Inoue H, Honda T, Nagai K, et al. Ultra-high magnification endoscopic observation of carcinoma in situ of the esophagus. Dig Endosc 1997;9:16-18.

46. Inoue $\mathrm{H}$, Kaga M, Ikeda $\mathrm{H}$, et al. Magnification endoscopy in esophageal squamous cell carcinoma: a review of the intrapapillary capillary loop classification. Ann Gastroenterol 2015;28:41-48.

47. Inoue H, Honda T, Yoshida T, et al. Ultra-high magnification endoscopy of the normal esophageal mucosa. Dig Endosc 1996;8:134-138.

48. Arima M, Tada M, Arima H. Evaluation of microvascular patterns of superficial esophageal cancers by magnifying endoscopy. Esophagus 2005;2:191-197.

49. Goda K, Tajiri H, Ikegami M, et al. Magnifying endoscopy with narrow band imaging for predicting the invasion depth of superficial esophageal squamous cell carcinoma. Dis Esophagus 2009;22:453-460.

50. Katada C, Tanabe S, Wada T, et al. Retrospective assessment of the diagnostic accuracy of the depth of invasion by narrow band imaging magnifying endoscopy in patients with superficial esophageal squamous cell carcinoma. J Gastrointest Cancer 2019;50:292-297.

51. Oyama T, Inoue $\mathrm{H}$, Arima $\mathrm{M}$, et al. Prediction of the invasion depth of superficial squamous cell carcinoma based on microvessel morphology: magnifying endoscopic classification of the Japan Esophageal Society.
Esophagus 2017;14:105-112.

52. Kim SJ, Kim GH, Lee MW, et al. New magnifying endoscopic classification for superficial esophageal squamous cell carcinoma. World J Gastroenterol 2017;23:4416-4421.

53. Ishihara R, Takeuchi Y, Chatani R, et al. Prospective evaluation of narrow-band imaging endoscopy for screening of esophageal squamous mucosal high-grade neoplasia in experienced and less experienced endoscopists. Dis Esophagus 2010;23:480-486.

54. Gruner M, Denis A, Masliah C, et al. Narrow-band imaging versus Lugol chromoendoscopy for esophageal squamous cell cancer screening in normal endoscopic practice: randomized controlled trial. Endoscopy 2021:53:674-682.

55. Dobashi A, Goda K, Furuhashi H, et al. Diagnostic efficacy of dual-focus endoscopy with narrow-band imaging using simplified dyad criteria for superficial esophageal squamous cell carcinoma. J Gastroenterol 2019;54:501-510.

56. Goda K, Dobashi A, Yoshimura N, et al. Dual-focus versus conventional magnification endoscopy for the diagnosis of superficial squamous neoplasms in the pharynx and esophagus: a randomized trial. Endoscopy 2016;48:321-329.

57. Kastelein F, van Olphen SH, Steyerberg EW, Spaander MCW, Bruno MJ, ProBar-Study Group. Impact of surveillance for Barrett's oesophagus on tumour stage and survival of patients with neoplastic progression. Gut 2016;65:548-554.

58. Sharma P, Bergman JJGHM, Goda K, et al. Development and validation of a classification system to identify high-grade dysplasia and esophageal adenocarcinoma in Barrett's esophagus using narrow-band imaging. Gastroenterology 2016;150:591-598.

59. American Gastroenterological Association, Spechler SJ, Sharma P, Souza RF, Inadomi JM, Shaheen NJ. American gastroenterological association medical position statement on the management of Barrett's esophagus. Gastroenterology 2011;140:1084-1091.

60. Sharma P, Hawes RH, Bansal A, et al. Standard endoscopy with random biopsies versus narrow band imaging targeted biopsies in Barrett's oesophagus: a prospective, international, randomised controlled trial. Gut 2013;62:15-21.

61. Qumseya BJ, Wang H, Badie N, et al. Advanced imaging technologies increase detection of dysplasia and neoplasia in patients with Barrett's esophagus: a meta-analysis and systematic review. Clin Gastroenterol Hepatol 2013;11:1562-1570.e1-e2.

62. Sharma P, Bansal A, Mathur S, et al. The utility of a novel narrow band imaging endoscopy system in patients with Barrett's esophagus. Gastrointest Endosc 2006;64:167-175.

63. Kara MA, Ennahachi M, Fockens P, ten Kate FJW, Bergman JJGHM. Detection and classification of the mucosal and vascular patterns (mucosal morphology) in Barrett's esophagus by using narrow band imaging. Gastrointest Endosc 2006;64:155-166.

64. Singh R, Anagnostopoulos GK, Yao K, et al. Narrow-band imaging with magnification in Barrett's esophagus: validation of a simplified grading system of mucosal morphology patterns against histology. Endoscopy 2008;40:457-463.

65. Silva FB, Dinis-Ribeiro M, Vieth M, et al. Endoscopic assessment and grading of Barrett's esophagus using magnification endoscopy and narrow-band imaging: accuracy and interobserver agreement of different classification systems (with videos). Gastrointest Endosc 2011;73:7-14.

66. Lipman G, Bisschops R, Sehgal V, et al. Systematic assessment with I-SCAN magnification endoscopy and acetic acid improves dysplasia detection in patients with Barrett's esophagus. Endoscopy 2017;49:12191228.

67. Pohl J, May A, Rabenstein T, Pech O, Ell C. Computed virtual chromoendoscopy: a new tool for enhancing tissue surface structures. Endoscopy 2007;39:80-83.

68. Osawa H, Yamamoto H, Yamada N, et al. Diagnosis of endoscopic Barrett's esophagus by transnasal flexible spectral imaging color enhance- 
ment. J Gastroenterol 2009;44:1125-1132.

69. Pohl J, May A, Rabenstein T, et al. Comparison of computed virtual chromoendoscopy and conventional chromoendoscopy with acetic acid for detection of neoplasia in Barrett's esophagus. Endoscopy 2007;39:594-598.

70. Osawa H, Yamamoto H. Present and future status of flexible spectral imaging color enhancement and blue laser imaging technology. Dig Endosc 2014;26 Suppl 1:105-115.

71. Li YX, Shen L, Yu HG, Luo HS, Yu JP. Fujinon intelligent color enhancement for the diagnosis of early esophageal squamous cell carcinoma and precancerous lesion. Turk J Gastroenterol 2014;25:365-369.

72. Codipilly DC, Qin Y, Dawsey SM, et al. Screening for esophageal squamous cell carcinoma: recent advances. Gastrointest Endosc 2018;88:413426

73. Sharma P, Savides TJ, Canto MI, et al. The American Society for Gastrointestinal Endoscopy PIVI (preservation and incorporation of valuable endoscopic innovations) on imaging in Barrett's esophagus. Gastrointest Endosc 2012;76:252-254

74. Hoffman A, Korczynski O, Tresch A, et al. Acetic acid compared with i-scan imaging for detecting Barrett's esophagus: a randomized, comparative trial. Gastrointest Endosc 2014;79:46-54

75. Diao W, Huang X, Shen L, Zeng Z. Diagnostic ability of blue laser imaging combined with magnifying endoscopy for early esophageal cancer Dig Liver Dis 2018;50:1035-1040

76. Tomie A, Dohi O, Yagi N, et al. Blue laser imaging-bright improves endoscopic recognition of superficial esophageal squamous cell carcinoma. Gastroenterol Res Pract 2016;2016:6140854.

77. Kobayashi K, Miyahara R, Funasaka K, et al. Color information from linked color imaging is associated with invasion depth and vascular diameter in superficial esophageal squamous cell carcinoma. Dig Endosc 2020;32:65-73

78. Nakamura K, Urabe Y, Oka S, et al. Usefulness of linked color imaging in the early detection of superficial esophageal squamous cell carcinomas. Esophagus 2021;18:118-124.

79. de Groof AJ, Swager AF, Pouw RE, et al. Blue-light imaging has an additional value to white-light endoscopy in visualization of early Barrett's neoplasia: an international multicenter cohort study. Gastrointest Endosc 2019;89:749-758.

80. Tokunaga M, Matsumura T, Ishikawa K, et al. The efficacy of linked color imaging in the endoscopic diagnosis of barrett's esophagus and esoph- ageal adenocarcinoma. Gastroenterol Res Pract 2020;2020:9604345.

81. Takeda T, Nagahara A, Ishizuka K, et al. Improved visibility of Barrett's esophagus with linked color imaging: inter- and intra-rater reliability and quantitative analysis. Digestion 2018;97:183-194.

82. de Groof AJ, Fockens KN, Struyvenberg MR, et al. Blue-light imaging and linked-color imaging improve visualization of Barrett's neoplasia by nonexpert endoscopists. Gastrointest Endosc 2020;91:1050-1057.

83. Subramaniam S, Kandiah K, Schoon E, et al. Development and validation of the international blue light imaging for Barrett's neoplasia classification. Gastrointest Endosc 2020;91:310-320.

84. Ohmori M, Ishihara R, Aoyama K, et al. Endoscopic detection and differentiation of esophageal lesions using a deep neural network. Gastrointest Endosc 2020;91:301-309.e1.

85. Fukuda H, Ishihara R, Kato Y, et al. Comparison of performances of artificial intelligence versus expert endoscopists for real-time assisted diagnosis of esophageal squamous cell carcinoma (with video). Gastrointest Endosc 2020;92:848-855.

86. Guo L, Xiao X, Wu C, et al. Real-time automated diagnosis of precancerous lesions and early esophageal squamous cell carcinoma using a deep learning model (with videos). Gastrointest Endosc 2020;91:41-51.

87. Everson M, Herrera L, Li W, et al. Artificial intelligence for the real-time classification of intrapapillary capillary loop patterns in the endoscopic diagnosis of early oesophageal squamous cell carcinoma: a proof-ofconcept study. United European Gastroenterol J 2019;7:297-306.

88. Shimamoto Y, Ishihara R, Kato Y, et al. Real-time assessment of video images for esophageal squamous cell carcinoma invasion depth using artificial intelligence. J Gastroenterol 2020;55:1037-1045.

89. van der Sommen F, Zinger S, Curvers WL, et al. Computer-aided detection of early neoplastic lesions in Barrett's esophagus. Endoscopy 2016;48:617-624.

90. Ebigbo A, Mendel R, Probst A, et al. Computer-aided diagnosis using deep learning in the evaluation of early oesophageal adenocarcinoma. Gut 2019;68:1143-1145.

91. Hashimoto R, Requa J, Dao T, et al. Artificial intelligence using convolutional neural networks for real-time detection of early esophageal neoplasia in Barrett's esophagus (with video). Gastrointest Endosc 2020;91:1264-1271.e1.

92. Struyvenberg MR, de Groof AJ, van der Putten J, et al. A computer-assisted algorithm for narrow-band imaging-based tissue characterization in Barrett's esophagus. Gastrointest Endosc 2021;93:89-98. 